on kinetic measurements and it gives many examples based chiefly on redox reactions in aqueous media. These give very great food for thought, and on the inorganic side of trace chemistry they might well have sparked off a new frontier. Their importance, however, is largely overshadowed by Walsh's evolution of atomic absorption spectroscopy which is virtually specific for metallic elements and which has been supplemented in sensitivity more recently by the advent of atomic fluorescence spectroscopy. Whilst, therefore, it is my opinion that the sensitivity, specificity and rapidity of atomic spectroseopy are analytically more advantageous in almost all cases, there is absolutely no doubt that, for organic or molecular problems, kinetic reactions are well to the forefront in interest and potential at the present time.

The book is well written and well produced. The mathematical treatment is clear and concise and need deter no one from reading this text. Whatever its impact may be on inorganic analysis, there is no doubt in my mind that this book will play a significant part over the next few years in shaping the thinking of analytical scientists concerned with organic analysis. New frontiers present an unavoidable challenge. They are here in this book.

T. S. WEST

\section{REFLECTANCE SPECTROSCOPY}

\section{Modern Aspects of Reflectance Spectroscopy}

Edited by Wesley W. Wendlandt. (Proceedings of the American Chemical Society Symposium, September 11-12, 1967; Chicago, Illinois.) Pp. $x+254$. (Plenum: New York, 1968.) $\$ 12.50$

THIs book is a collection of the papers presented at the American Chemical Society Symposium on Reflectanco Spectroscopy. Compared with absorption spectroscopy, reflexion studies have been comparatively neglected until recently. Now, with the ready availability of instruments for the direct recording of ultraviolet, visible and infrared spectra, there is a wide range of problems that can more casily be solved using reflexion rather than absorption methods.

As most materials reflect a composite of specular and diffuse radiation, it is scarcely to be expected that the theory of reflexion from real surface would be simple. The present status of diffuse reflectance theory, however, is ably reviewed in the first contribution, which directs attention to the pitfalls of using "standard theory" for all materials. Throughout the rest of the book there tends to be a marked absence of basic theory and most of the papers deal with technical applications of an empirical type. Many of these are of considerable industrial importance, and, as most of the substances studied have far from ideal surfaces in which multiple reflexion takes place, the lack of theory is perhaps justified. On this account the appeal of the book will be very much greater to the practical spectroscopist wishing to extend his knowledge of techniques rather than to the more theoretically inclined scientist who uses the reflexion technique to gain information on optical constants. Although most of the papers doal with reflexion in the visible region, there is adequate coverage of the use of internal reflectance spectroscopy (ATR) in the infrared. Many of the contributions describe special techniques such as high temperature reflectance spectroscopy, reflectance from compacted powders, identification of gas chromatographic fractions, and other microsampling methods.

The book is well illustrated with diagrams and pictures of apparatus. It is reproduced directly from the typewriter, which no doubt has kept the price within reasonable limits. It can be warmly recommended for the industrial spectroscopist who wishes to further his knowledge of spectroscopic techniques for dealing with difficult materials.

(x. R. WILKINSON

\section{FROM IONS TO HELICES}

\section{Structure and Bonding}

Vol. 4. Edited by C. K. Jørgensen, J. B. Neilands, Sir Ronald S. Nyholm, D. Reinen and R. J. P. Williams. Pp. iv + 229. (Springer-Verlag: Berlin and New York, 1968.) $48 \mathrm{DM} ; \$ 12$.

THIS is the fourth of a series appearing at irregular intervals and dealing with structure and bonding in inorganic chemistry, chemical physics and biochemistry. As in the preceding volume, there are only three articles. Two of these are encyclopaedic reviews and the third is more akin to an original paper.

Two-thirds of the volume is taken up by F. Hulliger's "Crystal Chemistry of Chalcogenides and Pnictides of the Transition Elements". This extensive survey of the structures, electrical and magnetic properties of compounds of the elements of groups VB and VIB of the Periodic Table contains 532 references, 34 pages of tables and 65 of the 77 figures in the volume. One half of a shorter article on "Quantum Chemical Studies of the Submolecular Structure of the Nucleic Acids" by S. Fraga and C. Valdemoro consists of tables and references. Tabulations of, for example, bond lengths and angles of purine and pyrimidine bases, $\pi$-electron charges, bond orders, orbital and transition energies and of oscillator strengths form the most useful feature of this review of theoretical work on the fundamental units of nucleic acids. A tentative explanation of coding specificity is given on the basis of electron density distribution for stacked bases. Finally, there is a short contribution "Ionic Radii and Enthalpies of Hydration of Ions" by D. F. C. Morris. A new set of ionic radii is given for the alkali metal and halide ions, based on the minima in electron density in crystals. These radii differ markedly from conventional Pauling and Goldschmidt radii, those of the cations being larger and of the anions smaller. The radii are used to estimate absolute enthalpies of hydration of the single ions.

The editors have still failed to adopt a uniform format for tabulating references. Inadequate editing has also left some rather bizarre English usage. Cumulative author and subject indices would be helpful in future volumes. As this expensive and rather diverse series is more likely to appeal to libraries than to individuals, hard covers would be preferable to the present limp bindings.

F. J. C. Rossotrt

\section{LATTICE DEFECTS}

\section{Lattice Defects and their Interactions}

By R. R. Hasiguti. Pp. vii + 1,144. (Gordon and Breach: New York and London, 1967.) Professional \$35; Reference $\$ 68$.

AfTer reading this book, I am sure the reader will remain somewhat puzzled as to the aim, purpose or usefulness of such a publication. Moreover, it is not until one reads the publicity "blurb" on the back flap of the book cover that the reason, or more accurately the excuse, becomes apparent. It turns out that in September 1965 a sym. posium on lattice defects and their interactions was held at the University of Hawaii in Honolulu, sponsored by the Physical Societies of America and Japan, and the book contains expanded papers based on the talks presented there.

Apart from such glaring weaknesses in presentation as the absence of a foreword or preface, the book abounds in errors both large and small. The editorial mistakes start at the contents page and continuc, in varying degrees, almost throughout this bloated volume of 1,144 pages. Typical is the interchange of figures between non-related papers. For example, Fig. 1 of the article by Hasiguti (which starts on page 201 and not page 181) 